\title{
Novel hydroxyapatite/chitosan bilayered scaffold for osteochondral tissue-engineering applications: Scaffold design and its performance when seeded with goat bone marrow stromal cells
}

\author{
Joaquim M. Oliveiraa ${ }^{\mathrm{a}, \mathrm{b}}$, Márcia T. Rodrigues ${ }^{\mathrm{a}, \mathrm{b}}$, Simone S. Silva ${ }^{\mathrm{a}, \mathrm{b}}$, Patrícia B. Malafaya ${ }^{\mathrm{a}, \mathrm{b}}$, \\ Manuela E. Gomes ${ }^{\mathrm{a}, \mathrm{b}}$, Carlos A. Viegas ${ }^{\mathrm{c}}$, Isabel R. Dias ${ }^{\mathrm{c}}$, Jorge T. Azevedo ${ }^{\mathrm{d}}$, \\ João F. Mano ${ }^{\mathrm{a}, \mathrm{b}}$, Rui L. Reis ${ }^{\mathrm{a}, \mathrm{b}, *}$ \\ a3B's Research Group - Biomaterials, Biodegradables and Biomimetics, Campus de Gualtar, 4710-057-Braga, Portugal \\ ${ }^{\mathrm{b}}$ Department of Polymer Engineering, University of Minho, Campus de Azurém, 4800-058-Guimarães, Portugal \\ ${ }^{\mathrm{c}}$ Department of Veterinary Sciences, University of Trás-os-Montes e Alto Douro, Quinta dos Prados, 5000-911-Vila Real, Portugal \\ ${ }^{\mathrm{d}}$ Department of Animal Science, University of Trás-os-Montes e Alto Douro, Quinta dos Prados, 5000-911-Vila Real, Portugal
}

Received 11 April 2006; accepted 26 July 2006

Available online 30 August 2006

\begin{abstract}
Recent studies suggest that bone marrow stromal cells are a potential source of osteoblasts and chondrocytes and can be used to regenerate damaged tissues using a tissue-engineering (TE) approach. However, these strategies require the use of an appropriate scaffold architecture that can support the formation de novo of either bone and cartilage tissue, or both, as in the case of osteochondral defects. The later has been attracting a great deal of attention since it is considered a difficult goal to achieve. This work consisted on developing novel hydroxyapatite/chitosan (HA/CS) bilayered scaffold by combining a sintering and a freeze-drying technique, and aims to show the potential of such type of scaffolds for being used in TE of osteochondral defects. The developed HA/CS bilayered scaffolds were characterized by Fourier transform infra-red spectroscopy, X-ray diffraction analysis, micro-computed tomography, and scanning electron microscopy (SEM). Additionally, the mechanical properties of HA/CS bilayered scaffolds were assessed under compression. In vitro tests were also carried out, in order to study the water-uptake and weight loss profile of the HA/CS bilayered scaffolds. This was done by means of soaking the scaffolds into a phosphate buffered saline for 1 up to 30 days. The intrinsic cytotoxicity of the HA scaffolds and HA/CS bilayered scaffolds extract fluids was investigated by carrying out a cellular viability assay (MTS test) using Mouse fibroblastic-like cells. Results have shown that materials do not exert any cytotoxic effect. Complementarily, in vitro (phase I) cell culture studies were carried out to evaluate the capacity of HA and CS layers to separately, support the growth and differentiation of goat marrow stromal cells (GBMCs) into osteoblasts and chondrocytes, respectively. Cell adhesion and morphology were analysed by SEM while the cell viability and proliferation were assessed by MTS test and DNA quantification. The chondrogenic differentiation of GBMCs was evaluated measuring the glucosaminoglycans synthesis. Data showed that GBMCs were able to adhere, proliferate and osteogenic differentiation was evaluated by alkaline phosphatase activity and immunocytochemistry assays after 14 days in osteogenic medium and into chondrocytes after 21 days in culture with chondrogenic medium. The obtained results concerning the physicochemical and biological properties of the developed HA/CS bilayered scaffolds, show that these constructs exhibit great potential for their use in TE strategies leading to the formation of adequate tissue substitutes for the regeneration of osteochondral defects.
\end{abstract}

(C) 2006 Elsevier Ltd. All rights reserved.

Keywords: Hydroxyapatite; Chitosan; Bilayered scaffold; Osteochondral tissue engineering; Stromal cells; Autologous model

\footnotetext{
*Corresponding author. 3B's Research Group-Biomaterials, Biodegradables and Biomimetics, Campus de Gualtar, 4710-057-Braga, Portugal. Tel.: + 351253604781 ; fax: + 351253604492 .

E-mail address: rgreis@dep.uminho.pt (R.L. Reis).
}

\section{Introduction}

In the skeleton, articular cartilages allows a stable movement with near frictionless and consequently act as a unique protective interface for the underlying bone. 
This is achieved in part, since articular cartilages resists to compressive forces due to the ability to distribute loads $[1,2]$. General features of cartilage tissue includes: (i) a small number of chondrocytes with low proliferation rate and having both catabolic and anabolic functions, (ii) a high content of water where metabolites and a large amount of electrolytes are dissolved, (iii) an abundant extracellular matrix (ECM) composed by different types of collagens (mainly type II) and proteoglycan aggrecan, which is mainly responsible for the elasticity, and (iv) possess no nerve and vascular systems [1,3]. Actually, the different cell numbers, organization and distribution, as well as organic and water content across cartilage are responsible for the existence of three distinct layers with respect to depth, i.e. superficial, middle and deep [4]. In this respect, Kuettner et al. [4] have suggested that the variations among articular cartilages is mainly due to significant changes in biochemical composition and biomechanical properties of the three layers.

It is well known that cartilage has a limited regeneration capacity upon damage. In certain extent, this is explained by the fact of being an avascular tissue; regenerative cells cannot migrate to the defect void unless the lesion goes beyond the subchondral bone plate $[5,6]$. Therefore, a regenerative response will be only possible when it is provided an artificial access by the marrow [7]. This consideration is subjacent on several clinical strategies that are currently employed on the treatment of small cartilage lesions namely, the subchondral abrasion, Pridie perforations, micro-fracture, and transplantation of osteochondral plugs [6,8-10]. Although, in most cases after clinical intervention the repaired tissue tends to degenerate and occur the formation of the undesired fibrocartilage $[5,11,12]$. More recently, it was reported an alternative approach, which consists on injecting autologous chondrocytes at the defect void [13-15]. Even though, this strategy does not avoid the excision of healthy cartilage from the joint for further expansion of the freshly isolated chondrocytes in vitro. Despite the encouraging results, there are a few critical requirements for the success of this approach. For example, the need to obtain high cell numbers, while maintaining chondrocyte functions. In this respect, it is well known $[16,17]$ that conditions favouring maintenance of phenotype are usually different from those that favour a high cell density, and consequently there are limitations in the number of cells obtained in vitro for subsequent clinical application. Therefore, the low rate of success especially in large lesions and in older people, and the procedural constraints are the major drawback of these techniques [18].

In order to eliminate donor site morbidity, which is one the major limitation of autografts, several tissue-engineered (TE) cartilaginous cell-scaffolds constructs have been proposed $[19,20]$. But, since we have been able to gain new insights related with the role of subchondral bone, it seems obvious the enormous implications in the field of TE namely, in respect to the development of more adequate scaffolds architectures for cartilage healing. In this respect, several authors have been proposing the use of bilayered osteochondral constructs for the improved regeneration of cartilage defects [21-23]. Basically, this conceptual approach consists on developing a single $3 \mathrm{D}$ porous structure that combines a mechanical support resembling the subchondral bone (bone-like layer), while also providing a chondrogenic support in the top for the repairing of cartilage (cartilage-like layer) [24,25]. Materials like hydroxyapatite (HA) [26-28] and chitosan (CS) [29-31] have been widely employed to develop suitable $3 \mathrm{D}$ supports for applications in TE of bone and cartilage, respectively. Therefore, on the basis of the osteochondral approaches, the development of bilayered osteochondral scaffolds combining both HA and CS layers thus seems a good approach. Although, a strong mechanical interface between mineral substrate and polymer matrix is required for preventing a premature failure of the scaffold. Schek et al. [25] has been described the use of poly lactic acid (PLA) rods for connecting a HA and PLA phases of a biphasic composite scaffold. Nevertheless, the effect of the polymeric rods on bone and cartilage regeneration is not studied. Therefore, there is the need of more simple and reliable strategies to manufacture bilayered scaffolds for osteochondral applications.

Besides the choice of adequate materials and the optimization of the mechanical properties and architecture for the scaffolds, TE strategies requires the use of cell sources, that should be viable in terms of clinical practice and that can be effective in new tissue formation. Research focused on tissue regeneration by means of using mesenchymal stem cells (MSCs) is increasingly attracting a great deal of attention, since MSCs have the ability to differentiate into various mesenchymal lineages [32-34] under specific culture conditions [35]. In fact, MSCs are one of the most promising candidates for transplantation after seeding into TE implants [36-39].

In this study it is described the developmental route, physicochemical characterization and biological evaluation of novel 3D macroporous HA/CS bilayered scaffolds. HA scaffolds (bone-like layer) were firstly produced by means of sintering. Then, the CS porous layer (cartilage-like layer) was obtained by means of freeze-drying a CS solution poured onto the top of the HA scaffolds. The physicochemical characterization of both organic and inorganic layers was performed by Fourier transform infra-red (FTIR) spectroscopy, X-ray diffraction (XRD) analysis, micro-computed tomography ( $\mu$-CT), and scanning electron microscopy attached with an X-ray detector (SEM/ EDS). The mechanical properties of the HA, CS porous layers and HA/CS bilayered scaffolds were assessed by compression tests. In vitro tests were also carried out to investigate the water-uptake and weight loss behaviour of the HA/CS bilayered scaffolds by soaking into a phosphate buffered saline (PBS) for 1 up to 30 days.

The intrinsic cytotoxicity of the HA porous layer and HA/CS bilayered scaffolds leachables was examined by 
carrying out a cellular viability assay (MTS test) using Mouse fibroblastic-like cells, which were previously in contact with the different concentrations of the scaffolds extract fluids. Moreover, a preliminary in vitro cultivation, proliferation and differentiation study was performed upon seeding of goat bone marrow stromal cells (GBMCs) onto HA and CS layers (Phase I). GBMCs have been shown to present high proliferation and viability rates in fresh or cryopreserved cultures. These cells are quite stable in 2D cultures and differentiate into osteogenic and chondrogenic phenotypic cells in the presence of supplemented osteogenic and chondrogenic media, respectively. Beside that, it is possible to use an autologous approach with the goat animal model and, in future experiments, evaluate in vivo, the osteochondral constructs functionality of HA and CS using marrow cells harvested from same animal implanted with the in vitro TE construct. Relative GBMCs viability and proliferation was assessed by MTS test and DNA quantification, while cellular adhesion and morphology was investigated by SEM. Osteogenic differentiation was assessed by alkaline phosphatase (ALP) activity and immunocytochemistry techniques for type I collagen and osteopontin. Glucosaminoglycans (GAGs) quantification assay was performed to evaluate chondrogenic differentiation.

Future studies will be designed to investigate the capacity of the HA/CS bilayered scaffolds to favour simultaneous osteoblasts and chondrocytes proliferation and differentiation upon seeding GBMCs, leading to the formation of adequate tissue substitutes for the regeneration of osteochondral defects. With this approach it is aimed to develop an autologous model for further implantantion in vivo.

\section{Materials and methods}

\subsection{Synthesis of $H A$}

Analytical reagent grade calcium hydroxide, $\mathrm{Ca}(\mathrm{OH})_{2}$ (Riedel-de Haën, Germany) and ortho-phosphoric acid, $\mathrm{H}_{3} \mathrm{PO}_{4}$ (Panreac, Spain) were used on the synthesis of the HA powders. An controlled drop-wise automated apparatus was developed by means of using a peristaltic pump (Gilson Miniplus 3, France) for adding a diluted solution of ortho-phosphoric acid to the calcium hydroxide solution, in a reaction vessel. Synthesis conditions were adjusted to obtain a stoichiometric $\mathrm{HA}$, i.e. $\mathrm{Ca} / \mathrm{P}$ ratio of 1.67. After complete addition of the acid solution, the final $\mathrm{pH}$ of medium was adjusted to 11 with concentrated ammonium hydroxide (Riedel-de Haën, Germany). Vigorous stirring was continued during HA precipitation. The supernatant was removed after $24 \mathrm{~h}$ of maturation, and the precipitate filtered under vacuum. The resulting filtrate was dried at $60{ }^{\circ} \mathrm{C}$ for $24 \mathrm{~h}$ and milled in a mortar until obtaining a fine powder.

\subsection{Preparation of $H A$ scaffolds and $H A / C S$ bilayered scaffolds}

HA/CS bilayered scaffolds were produced by adopting a two step procedure. Firstly, HA porous layer (bone-like layer) with $10 \mathrm{~mm}$ height and $8 \mathrm{~mm}$ diameter were obtained by means of impregnating a polyurethane (PU) sponge with HA powders, as previously reported by Oliveira et al. [40]. The elimination of the organic matrix consisted on burning the impregnated sponges in the furnace (Fornocerâmica-ATR
901, Portugal) at $900^{\circ} \mathrm{C}$ for $24 \mathrm{~h}$, followed by sintering at $1300^{\circ} \mathrm{C}$ for $3 \mathrm{~h}$, at ramp rate of $2.5^{\circ} \mathrm{C} \mathrm{min}^{-1}$. Secondly, a $3 \mathrm{wt} \% \mathrm{CS}$ solution was prepared by dissolving CS of medium molecular weight (Aldrich, Germany) and a degree of deacetylation of $\sim 85 \%$ in $0.2 \mathrm{M}$ acetic acid solution. The bilayered HA/CS scaffolds were fabricated by placing the HA scaffolds into cylindrical silicon moulds $(20 \times 8 \mathrm{~mm})$ and transferring the $3 \mathrm{wt} \% \mathrm{CS}$ solution. To guarantee that CS interpenetrated into the HA scaffolds it was left resting for $1 \mathrm{~min}$ at room temperature. Moulds were freeze at $-80^{\circ} \mathrm{C}$ and lyophilized (Telstar-Cryodos -80 , Spain) up to 4 days to complete remove the frozen solvent, and allow obtaining the "cartilage-like layer' on the top of the 'bone-like layer'. Then, HA/CS bilayered scaffolds were neutralized using a $0.1 \mathrm{M}$ sodium hydroxide solution as previously described elsewhere [41], freeze at $-80^{\circ} \mathrm{C}$ and once lyophilized. Finally, the resulting $\mathrm{HA} / \mathrm{CS}$ bilayered scaffolds were sterilized using ethylene oxide before carrying out the cell culture studies.

\subsection{Physicochemical characterization}

\subsubsection{FTIR spectroscopy}

Infra-red spectra of specimen powders were recorded on a PerkinElmer spectrometer (Perkin-Elmer 1600 series equipment, USA). Prior analysis transparent $\mathrm{KBr}$ (Riedel-de Haën, Germany) pellets were prepared by mixing in the ratio of $1: 10$ of sample $/ \mathrm{KBr}(\mathrm{wt} / \mathrm{wt})$, followed by uniaxially pressing the powders under vacuum. All spectra were obtained between 4400 and $450 \mathrm{~cm}^{-1}$ at a $2 \mathrm{~cm}^{-1}$ resolution.

\subsubsection{XRD analysis}

X-ray diffractometer (Philips PW 1710, The Netherlands) employing $\mathrm{Cu}-\mathrm{K} \alpha$ radiation was used to investigate the cristallinity and phase content of the HA scaffolds on powder. Data was collected from 2 to $65^{\circ}$ $2 \theta$ values, with a step size of $0.02^{\circ}$, and a counting time of $2 \mathrm{~s} \mathrm{step}^{-1}$.

\subsubsection{Surface topography characterization}

The surface morphology and pore size of the HA scaffolds and HA/CS bilayered scaffolds were examined under the SEM/EDS (Leica Cambridge S-360, UK). Prior to the microstructure analysis, specimens were coated with gold using a Fisons Instruments Coater (Polaron SC 502, UK) with a current set at $18 \mathrm{~mA}$, for a coating time of $120 \mathrm{~s}$.

\subsubsection{Micro-computed tomography}

The qualitative information of the HA/CS bilayered scaffolds architecture was obtained by microtomography imaging using a Scanco 20 equipment (Scanco Medicals, Switzerland) with penetrative X-rays of $50 \mathrm{keV}$. The X-ray scans were acquired in high-resolution mode $(11 \mu \mathrm{m})$. Mimics ${ }^{\circledR}$ software (Materialise, Belgium) was used to visualize the 2D $\mathrm{X}$-ray sections images of the HA/CS bilayered scaffolds. From the CT data set, 300 slices of a region of interest corresponding to the interface between HA and CS was used to investigate the continuity of the HA/CS bilayered scaffolds. A customized threshold technique was used to enhance the CS contrast and remove noise.

\subsubsection{Mechanical testing}

Compression tests (dry state) were performed using a Universal Testing Machine (Instron 4505) possessing a load cell of $50 \mathrm{kN}$, at room temperature. The gauge length and diameter of all specimens was $16 \mathrm{~mm}$ and $8 \mathrm{~mm}$, respectively. Tests were conducted with a constant strain rate of $2 \mathrm{~mm} \mathrm{~min}^{-1}$, and up to failure or until $60 \%$ reduction in specimen height. The modulus $(E)$ was determined by linear regression from the slopes in the initial elastic portion of the stress-strain diagram. A minimum number of 10 specimens were tested, and then $E$ was averaged from the 10 measurements.

\subsubsection{Water uptake and weight loss studies}

Water uptake and weight loss of the HA scaffolds and HA/CS bilayered scaffolds were evaluated after immersion into a PBS (SigmaAldrich, Germany) solution at $\mathrm{pH} 7.4$ for time periods up to 30 days. 
All experiments were conducted at $37 \pm 1{ }^{\circ} \mathrm{C}$, in triplicate. Percentage of water uptake (WUs) after each time of immersion $(t)$ was calculated using Eq. (1), where $W_{\mathrm{d}}$ and $W_{\mathrm{w}}$ correspond to the weight of the HA/CS bilayered scaffolds in dry and wet state, respectively:

WUs, $t=\left[\left(W_{\mathrm{w}, t}-W_{\mathrm{d}}\right) / W_{\mathrm{d}}\right] \times 100$.

The percentage of weight loss (WLs) after each time of immersion $(t)$ was calculated using Eq. (2), where $W_{\mathrm{i}}$ and $W_{\mathrm{f}}$ corresponds to the weight they before and after immersion into PBS solution, respectively:

$\mathrm{WLs}, t=\left[\left(W_{\mathrm{f}, t}-W_{\mathrm{i}}\right) / W_{\mathrm{i}}\right] \times 100$.

\subsection{In vitro cell culture studies}

\subsubsection{Cytotoxicity screening}

MTS (3-(4,5-dimethylthiazol-2-yl)-5-(3-carboxymethoxyphenyl)-2-(4sulfophenyl)-2H-tetrazolium) test was performed to determine the cytotoxicity of HA porous scaffolds and HA/CS bilayered scaffolds leachables that might result from the processing methodology used to obtain the HA scaffolds and/or leachables of the polymeric component of the bilayered materials. Mouse fibroblastic-like cells (L929 cells; ECACC, UK), were cultured in basic medium: Dulbecco's Modified Eagle's Medium (DMEM), Sigma-Aldrich, USA) without phenol red supplemented with $10 \%$ foetal bovine serum, FBS (Gibco, UK) and antibioticantimycotic ( $1 \% \mathrm{~A} / \mathrm{B}$, Gibco, UK) solution containing 10,000 units $\mathrm{ml}^{-1}$ penicillin $\mathrm{G}$ sodium, $10,000 \mu \mathrm{g} \mathrm{ml}^{-1}$ streptomycin sulphate and $25 \mu \mathrm{g} \mathrm{ml}^{-1}$ amphotericin B as Fungizone ${ }^{\mathbb{R}}$ in $0.85 \%$ saline. L929 cells were incubated at $37^{\circ} \mathrm{C}$ in an atmosphere containing $5 \%$ of $\mathrm{CO}_{2}$, and after achieving confluence a cell suspension was prepared with a concentration of $8 \times 10^{4}$ cells ml $^{-1}$ and seeded onto 96-well plates. L929 cells were incubated for 3 days with different concentrations of HA and HA/CS bilayered scaffolds extracts $(25 \%, 50 \%, 75 \%$ and $100 \%)$. Eight replicates were considered per sample. Extracts of all samples were prepared as previously described by Gomes et al. [42].

L929 cells relative viability (\%) was determined for each extract concentration and compared to tissue culture polystyrene (TCPS). Latex extracts were used as a positive control of cellular death. All cytotoxicity tests were performed in triplicate.

\subsubsection{Isolation and culture of GBMCs}

Bone marrow stromal cells were isolated from the iliac crest of adult goats and cultured with basic culture medium-DMEM supplemented with $10 \% \mathrm{FBS}$ and $1 \% \mathrm{~A} / \mathrm{B}$. Cells were cultured until confluence and subcultured at $\mathrm{P} 1$ and $\mathrm{P} 2$ before seeding. The relative viability of GBMCs on the HA scaffolds was also determined by carrying out an MTS assay, after each time point. For this purpose, cells-HA scaffold constructs were transferred into a 48-well plate and washed twice with sterile PBS. Culture medium without FBS and without phenol red was mixed with MTS in a 5:1 ratio, added to the wells, until totally cover the constructs, and incubated for $3 \mathrm{~h}$ at $37^{\circ} \mathrm{C}$ in a $5 \% \mathrm{CO}_{2}$ incubator. After the incubation period, $100 \mu \mathrm{l}$ of MTS and medium mixture were transferred into each well of a 96-well plate and absorbance was read at $490 \mathrm{~nm}$.

\subsubsection{Seeding of GBMCS onto the HA porous layer and $3 D$ culturing (Phase IA)}

GBMCs cells were enzymatically lifted with $3 \mathrm{ml}$ of trypsin after reaching $80 \%$ of confluence at $\mathrm{P} 1$ or $\mathrm{P} 2$. A cell suspension was prepared and seeded onto the HA porous layer in a scaffold drop-wise manner, at a cellular density of $2.1 \times 10^{5} \mathrm{cells} \mathrm{m}^{-1}$. Cells/scaffolds constructs were cultured in 48-well plates for 3 days with basic medium in static conditions. For inducing osteogenic differentiation, cell-seeded scaffolds were cultured with an osteogenic media consisting of alpha-MEM (Minimal Essential Medium Eagle alpha modification, Sigma-Aldrich, USA) supplemented with osteogenic supplements namely, $10^{-8} \mathrm{M}$ dexamethasone (Sigma-Aldrich, USA), $50 \mu \mathrm{g} \mathrm{ml}^{-1}$ ascorbic acid (Sigma, USA) and $10 \mathrm{~mm} \beta$-glycerophosphate (Sigma, USA). The constructs were cultured for 3 days in static cultures with basal medium plus 14 days in osteogenic medium (17 days) and under dynamic conditions by using a lab rotator (Model DSR 2800 V, Digisystem Laboratory Instruments Inc., Taiwan). Samples were collected on day 0 ( $12 \mathrm{~h}$ after seeding), day 3 and day 17 for further studies.

\subsubsection{Seeding of GBMCs onto the CS porous layer and $3 D$ culturing (Phase IB)}

To induce chondrogenic differentiation, CS scaffolds were seeded with $2.5 \times 10^{5}$ cells and cultured for 7, 21 and 28 days with chondrogenic medium consisting of DMEM (Sigma-Aldrich, USA) supplemented with $10 \mathrm{\eta g} \mathrm{ml}^{-1}$ TGF- $\beta$ (Sigma-Aldrich, USA), ITS $+1(100 \times$ liquid media supplement, Sigma, USA), 0.1 m sodium pyruvate (Sigma-Aldrich, USA), $35 \mathrm{~mm}$ proline (Sigma-Aldrich, USA), $17 \mathrm{~mm}$ ascorbic acid (SigmaAldrich, USA) and $1 \mathrm{~mm}$ dexamethasone (Sigma-Aldrich, USA). The cell-scaffold constructs were also cultured under dynamic conditions by using a lab rotator system. Samples were retrieved after 7,21 and 28 days of chondrogenic culture. Before chondrogenic medium was added, samples were cultured for 3 days in basal medium in static conditions. In both cases, culture media were changed every $2-3$ days.

\subsubsection{Evaluation of GBMCs adhesion and morphology}

Culturing GBMCs adhesion and morphology was investigated by SEM analysis. For this purpose, after each culturing period, samples were removed from culture, washed in PBS, fixed in $2.5 \%$ glutaraldehyde, rinsed two times with PBS and dehydrated in series of ethanol concentrations. The samples were then dried at room temperature and sputter coated with gold before observation under the SEM.

\subsubsection{Assessment of GBMCs proliferation and differentiation}

GBMCs-HA and -CS construct celullarity was determined using a fluorimetric dsDNA quantification kit (PicoGreen, Molecular Probes). For this purpose, samples collected on days 0,3 and 17, were washed twice with a sterile PBS (Sigma, USA) solution and transferred into $1.5 \mathrm{ml}$ microtubes containing $1 \mathrm{ml}$ of ultra-pure water. GBMCs-HA and -CS were incubated for $1 \mathrm{~h}$ at $37^{\circ} \mathrm{C}$ in a water-bath and then stored in a $-80{ }^{\circ} \mathrm{C}$ freezer until testing. Prior to DNA quantification constructs were thawed and sonicated for $15 \mathrm{~min}$. Samples and standards (ranging between 0 and $2 \mu \mathrm{g} \mathrm{ml}^{-1}$ ) were prepared per each well of an opaque 96-well plate were added $28.7 \mu \mathrm{l}$ of sample or standard plus $71.3 \mu \mathrm{l}$ of PicoGreen solution and $100 \mu \mathrm{l}$ of Tris-EDTA buffer. Triplicates were made for each sample or standard. The plate was incubated for $10 \mathrm{~min}$ in the dark and fluorescence was measured on a microplate ELISA reader (BioTek, USA) using an emission of $490 \mathrm{~nm}$ and an absorbance wavelength of $520 \mathrm{~nm}$. A standard curve was created and sample DNA values were read off from the standard graph.

ALP activity was measured to evaluate osteoblastic differentiation. Cell-HA scaffold constructs used for DNA quantification assay were used to determine ALP levels. As cells were lysed during the above-mentioned procedure, both DNA and other cell-produced proteins were in suspension in the supernatant solution. So, to each well of a 96-well plate were added $20 \mu \mathrm{l}$ of sample plus $60 \mu \mathrm{l}$ of substrate solution: $0.2 \%(\mathrm{w} / \mathrm{v}) p$ nytrophenyl $(p N P)$ phosphate (Sigma, USA) in a substrate buffer: $1 \mathrm{~m}$ diethanolamine $\mathrm{HCl}$ (Merck, Germany), at $\mathrm{pH}$ 9.8. The plate was then incubated in the dark for $45 \mathrm{~min}$ at $37^{\circ} \mathrm{C}$. After the incubation period, $80 \mu \mathrm{l}$ of a stop solution: $2 \mathrm{M} \mathrm{NaOH}$ (Panreac, Spain) containing $0.2 \mathrm{~mm}$ EDTA (Sigma, USA), was added to each well. Standards were prepared with $10 \mu \mathrm{mol} \mathrm{ml}^{-1} p \mathrm{NP}$ and the stop solutions in order to achieve the final concentrations ranging between 0 and $0.3 \mu \mathrm{mol} \mathrm{ml}^{-1}$. Triplicates were made for each sample and standard. Absorbance was read at $405 \mathrm{~nm}$ and sample concentrations were read off from standard graph.

Immunocytochemistry technique was performed by fixing cell-HA scaffold constructs in an Accustain formalin solution, 10\% neutral buffered (Sigma-Aldrich, USA) for $1 \mathrm{~h}$ at $4{ }^{\circ} \mathrm{C}$, washing with PBS and including the constructs into methacrylate blocks. These blocks were cut into $10 \mu \mathrm{m}$ thick slides and kept overnight at $80^{\circ} \mathrm{C}$ before being used for subsequent immunocytochemistry analysis. The procedures 
immunocytochemistry were carried out following the instructions included in commercial kit: the RTU Vector Stain kit-Universal Elite ABC kit PK7200 (Vector Laboratories Inc., USA). This kit was used with a Peroxidase Substract Kit-DAB SK4100 (Vector Laboratories Inc., Burlingame, USA). For this study, samples were incubated with collagen type I (1/100, Chemicon, USA) for $1.6 \mathrm{~h}$ and the biotinylated secondary antibody was incubated for $1 \mathrm{~h}$ prior to wash and incubate the constructs with DAB for about $6 \mathrm{~min}$. Also an osteopontin antibody (1/100, Rabitt polyclonal to osteopontin, Abcam, UK) was tested using slides from the same constructs. Although in this particular case, a fluorescent secondary antibody was used instead of a biotinylated one and kept overnight at $80^{\circ} \mathrm{C}$. The metacrylate sections were incubated with osteopontin antibody, washed and then Alexa Fluor 488 secondary antibody (Molecular Probes, Invitrogen, UK) was added to cell-HA scaffold constructs. The incubation periods used were the same for both collagen type I and osteopontin antibodies. The observation of the constructs was performed using an Axio Imager Z1 microscope (Zeiss, Germany).

GAGs quantification assay [43] was used to determine extracellular chondrogenic matrix formation after days 7, 21 and 28 of chondrogenic medium culture. Cell-CS scaffold constructs used for this assay were the same used for ALP and DNA assays. GAGs standards were obtained by preparing a chondroitin sulphate solution ranging from 0 and $30 \mu \mathrm{g} \mathrm{ml}^{-1}$. In each well of a 96-well plate, $20 \mu \mathrm{l}$ of sample or standard were added in triplicates and then $250 \mu \mathrm{l}$ per well of dimethylmethylene blue (DMB, Sigma-Aldrich, USA) was added and mixed. The optical density was measured immediately at $525 \mathrm{~nm}$ on a microplate ELISA reader. A standard curve was created and GAGs sample values were read off from the standard graph.

\section{Results and discussion}

\subsection{Characterization}

The exploitation of a variety of biomaterials and cultured cells in TE approaches offers a wide range of possibilities for the successful repair of different skeleton damages. The ideal strategy for the treatment of osteochondral defects requires a scaffold architecture possessing a 'cartilage-like' layer (upper layer) and a 'bone-like' layer (bottom layer) [44]. With this approach, the porous bilayered structure is expected to act as a support for cells functions and ultimately, leading to the de novo formation of an articular cartilage-like tissue in the cartilage void, while providing a good fixation on the underlying bone.

Previously, it was shown [45] that it is possible to develop a 3D macroporous HA structures by impregnation of PU sponges with HA particles, followed by burning the organic template and sintering the ceramic at $1300^{\circ} \mathrm{C}$. Moreover, it is well known that a wide number of highly porous scaffold systems may be prepared by means of freezing a polymer solution and subsequently freezedrying. In this study, we developed a novel bilayered scaffold by means of pouring a $3 \mathrm{wt} \%$ CS solution upon the sintered HA scaffolds followed by a freeze-drying procedure. Fig. 1 shows the macroscopic appearance of the HA/CS bilayered scaffolds. The macro image shows two distinct layers, which corresponds to HA (bottom layer) and CS (upper layer). The improved stability at the inorganic-organic interface and overall integrity of the HA/CS bilayered scaffolds was achieved by partially

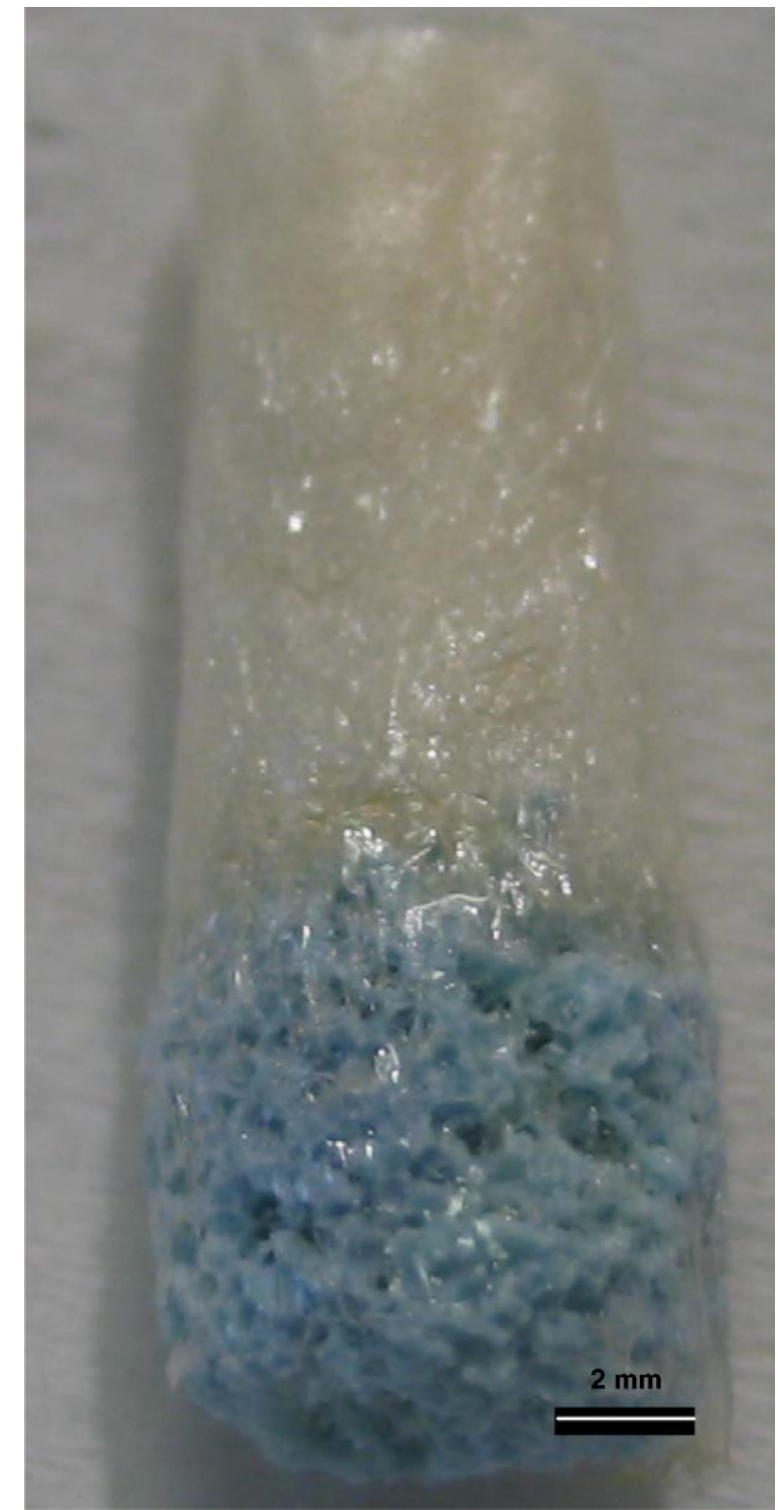

Fig. 1. Macroscopic appearance of the HA/CS bilayered scaffolds.

impregnating the porous ceramic layer with the polymeric one.

Fig. 2 shows the FTIR spectra of the HA and CS layers of the HA/CS bilayered scaffolds. The FTIR analysis revealed the presence of the typical bands of CS on the upper layer namely, the absorption bands of the amide I and amide II groups at 1650 and $1586 \mathrm{~cm}^{-1}(\theta)$, respectively $[46,47]$. On the other hand, the IR spectrum also exhibited the peaks at 900 and $1155 \mathrm{~cm}^{-1}(\mathbf{O})$ associated to saccharine structure, and aliphatic $\mathrm{C}-\mathrm{H}$ stretching bands in the region of $2996-882 \mathrm{~cm}^{-1}(x)$. The more intense and broad absorption band in the $\mathrm{CS}$ is attributed to the $\mathrm{N}-\mathrm{H}$ stretching and $\mathrm{O}-\mathrm{H}$ stretching vibration ( $\boldsymbol{\square}$ ) located in the spectral region of $3200-3500 \mathrm{~cm}^{-1}$.

Regarding the FTIR spectrum of lower layer of the HA/ CS bilayered scaffolds, it were detected intense absorption bands at 598 and $559 \mathrm{~cm}^{-1}(+)$, and $1020 \mathrm{~cm}^{-1}(\square)$, which are assigned to phosphate groups with the frequency of 


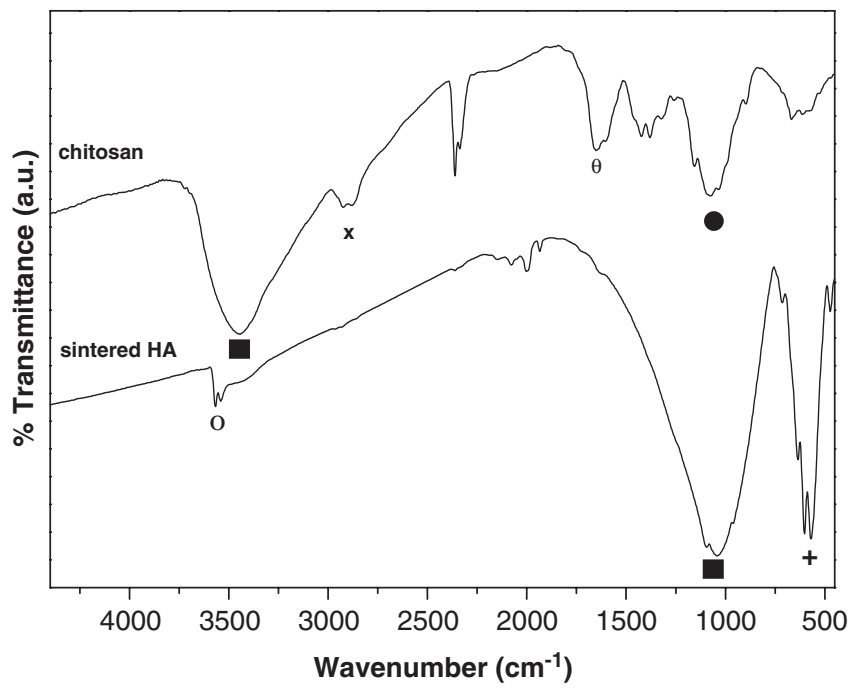

Fig. 2. FTIR spectra of HA and CS layers of the HA/CS bilayered scaffolds.

vibration $v 4$ and $v 3$, respectively. The small and sharp band observed at $3572 \mathrm{~cm}^{-1}$ (0) corresponds to the stretching mode of hydroxyl group, which is characteristic of calcium phosphates such as HA [48]. The FTIR data showed no typical peaks of the PU sponge in the HA layer after performing the heat treatments. This result is an important one, because it shows that no traces of PU sponge were present in the HA layer, thus avoiding the presence of organic matter that somehow could be responsible for eliciting some cytotoxic effect. Therefore, this result has shown that by means of using the burning and sintering cycle herein described, it is possible to completely eliminate the 'sacrifice matrix' consisting of PU sponge.

It has been reported that at temperatures higher than $1200^{\circ} \mathrm{C}$, HA became unstable and frequently loses the -OH groups, and transforms decomposition products such as $\beta$-tricalcium phosphates (TCP) $[48,49]$. When the temperature exceeds $1250^{\circ} \mathrm{C}$, an allotropic transformation may also occur and $\beta$-TCP may originate $\alpha$-TCP $[48,49]$. Although, in a previous work we have shown that the synthesized HA is highly stable upon sintering at $1300{ }^{\circ} \mathrm{C}$ for $3 \mathrm{~h}$, i.e. no $-\mathrm{OH}$ group loss was detected and no phase transformation observed [45]. Thus, understanding the sintering behaviour of HA allows us to control the chemical composition and design a porous ceramic structure with controlled grain size, microstructure and mechanical properties, since sintering temperature also has a dramatic effect on densification. Actually, it has been shown that a decrease in porosity, i.e. increase in particle agglomeration is accompanied by an increase in the mechanical strength, due to the homogeneity and more closed packed HA grains [50].

In this study, the XRD was also used to investigate the crystallinity and phase content of inorganic layer of the HA/CS bilayered scaffolds. Fig. 3 shows the XRD pattern of the ceramic porous layer (on powder) after burning the organic template at $900{ }^{\circ} \mathrm{C}$ followed by sintering at $1300{ }^{\circ} \mathrm{C}$

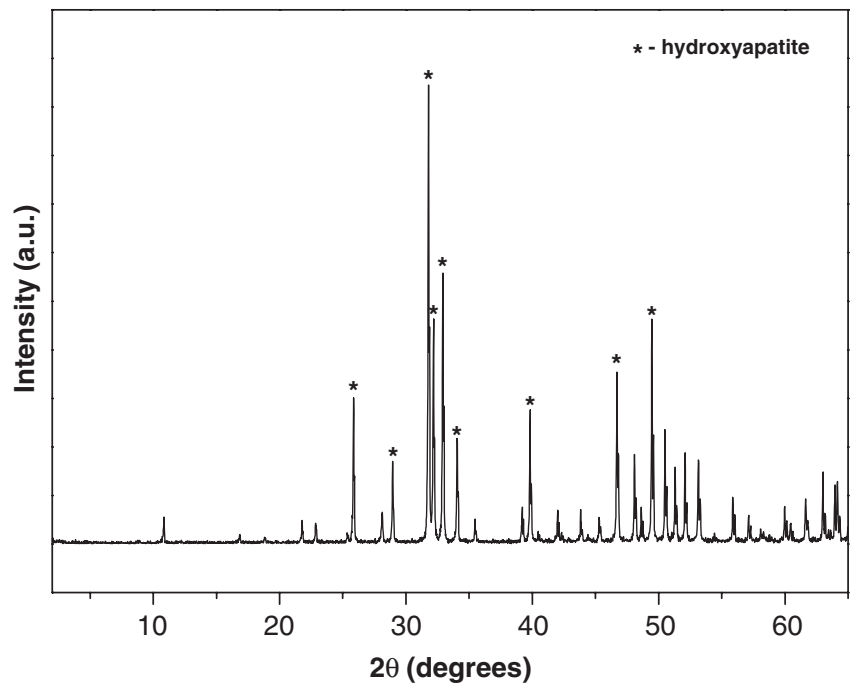

Fig. 3. XRD pattern of the HA scaffolds of the HA/CS bilayered scaffolds.

for $3 \mathrm{~h}$. The XRD data is in good attainment with the FTIR, showing that the ceramic layer consists of highly crystalline form of HA [51,52]. As expected, the pouring and freeze-drying of a CS solution upon the ceramic porous layer did not affect both crystallinity and phase content of the HA.

From the SEM images shown in Fig. 4, it can be seen that HA/CS bilayered scaffolds microarchitecture consists of a highly porous and open pore structure. Fig. 4A shows the interface of HA/CS bilayered scaffold at the surface, where it is possible to observe the two distinct porous layers. Fig. 4B shows a typical HA pore at the HA/CS interface, showing the good interpenetration of CS into the HA scaffolds. This observation suggests that a good bonding exist between the two layers, which is known to be a requisite necessary to assure a good integrity and functionality of the osteochondral construct (scaffold + cells). Moreover, the SEM examination of the HA scaffolds revealed that pores are highly interconnected and possess a size diameter in the range of $50-500 \mu \mathrm{m}$ (Fig. 4C).

Several authors $[53,54]$ have shown that freezing conditions, concentration of polymer and freeze-drying parameters has great influence on the final microstructure and degree of interconnectivity of the scaffolds. Fig. 4D shows the SEM micrograph of a CS pore at the typical transversal cross-section of CS layer. This study revealed that CS pores quite resembles a typical spongy 3D structure, with open pores, anisotropic porosity and pore size ranging from $20-600 \mu \mathrm{m}$. It is also possible to observe the formation of micro fibres during the freeze-drying process. This can be an advantage since these fibres can act as an additional anchor-framework for improved cells adhesion. Therefore, the results depicted in Fig. 4 have shown that by combining a sintering and freeze-drying technique it is possible to develop HA/CS bilayered scaffolds with an adequate pore size and pore distribution for ingrowths of cells and 

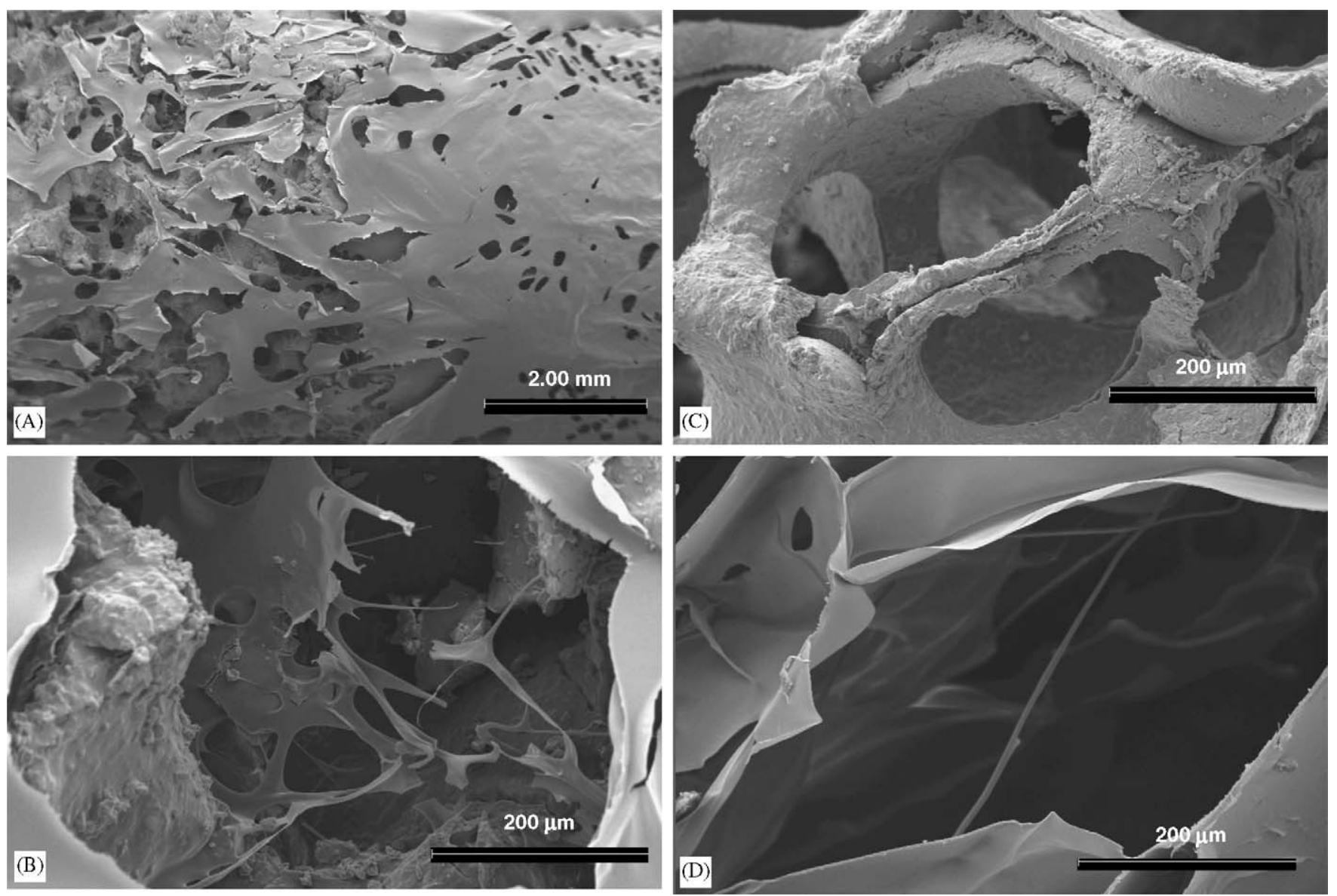

Fig. 4. SEM micrographs of the HA/CS bilayered scaffolds: interface (A), typical pore at interface (B), pore of HA scaffolds (C) and pore of CS layer (D).

diffusion of nutrients, while facilitating vascularization, and thus to be used in TE purposes $[55,56]$. Although, it is noteworthy that SEM analysis is only a reliable technique to obtain information about $2 \mathrm{D}$ systems, i.e. investigate the macro and micro-structure of the scaffold in a nondestructive way at the surface, and shows limited performance for assessing the pore interconnectivity of the materials. Moreover, the scaffold should be sectioned by destructive techniques towards obtaining the detailed information of their inner part using the SEM, thus the original morphology of the scaffold will be destroyed. Therefore, in this study the 3D architecture of the materials was investigated in a non-destructive way, by means of using a micro-CT analysis.

Fig. 5 shows the $\mu$-CT analysis of the HA/CS bilayered scaffolds. A customized threshold technique was carried out and has shown to be effective on assessing the pore size and interconnectivity of CS (Fig. 5A). From the $\mu$-CT 2D scans it was possible to assess that pore size is higher than those obtained by the SEM (surface study). Actually, the inner pores of CS was assessed to be up to $2 \mathrm{~mm}$ in length, which may be explained by the fact that $\mu$-CT allows to study the inner 3D architecture of the materials. Fig. 5B shows the 2D transversal view of the HA scaffolds, which corroborated the SEM findings. This results clearly showed that the HA pore network is highly interconnected. From Fig. 5C it became possible to observe that CS perfectly interpenetrated into the HA, thus showing the good continuity of the HA/CS bilayered scaffold. This result is encouraging since a strong mechanical interface between the HA and CS is required for the good performance of the construct.

Previous reported results have shown that the mean porosity of the HA scaffolds (bottom layer) of the HA/CS bilayered scaffolds consisted of $67.8 \pm 5.1 \%$ [45]. In this study, the percentage of porosity of the HA and CS layers were also determined (Fig. 5D). The results have shown that HA possess a porosity of $59.3 \pm 1.7 \%$, which is in good agreement with the previous reported data, and that CS layer consisted of $74.6 \pm 1.2 \%$. Therefore, the $\mathrm{HA} / \mathrm{CS}$ bilayered scaffolds have shown to possess adequate porosity [56] towards being used in TE scaffolding. Despite, the percentage of porosity at the interface was not possible to determine due to the limitation of the technique, i.e. since the coefficient of attenuation of HA is much higher that that of CS, the threshold applied for determining the porosity of HA layer (T300) is different from that for assessing the porosity of CS layer (T55). In fact, the observation of the dramatic lowering of porosity of CS layer at the interface consists of an artefact and is a 

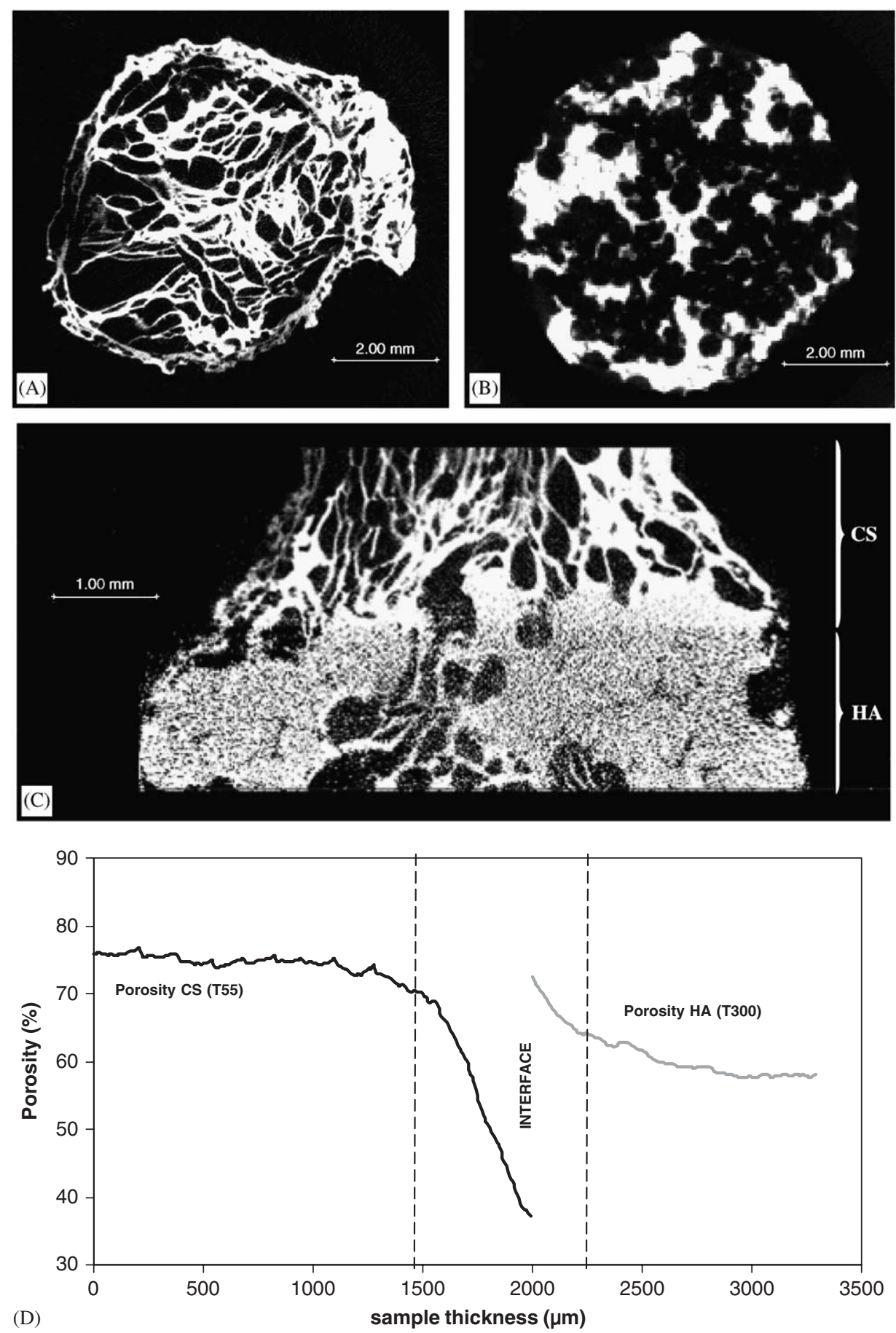

Fig. 5. $\mu$-CT images of the HA/CS bilayered scaffolds: transversal view of the CS scaffold (A), transversal view of the HA scaffold (B), and longitudinal view of the interface between HA (bottom layer) and CS (top layer) (C), and respective percentage of porosity.

consequence of the higher interference of HA. This data also shows that the overall integrity of the $\mathrm{HA} / \mathrm{CS}$ bilayered scaffolds was achieved by partially impregnating the porous ceramic layer with the polymeric one, and is restricted to an area of $750 \mu \mathrm{m}$ in length. Moreover, the results have shown that a physical interaction is responsible for the stability of the bilayered scaffolds at the interface between HA and CS. Therefore, another biopolymer that can be processed by freeze-drying may serve the same role as the CS, i.e. top layer of the bilayered scaffold.

To examine the mechanical properties of the HA/CS bilayered scaffolds, compression tests of the two layers were conducted separately, in dry conditions. The modulus (E) for the HA and CS in compression was found to be $153 \pm 12$ and $2.9 \pm 0.4 \mathrm{MPa}$, respectively. This results show that HA scaffold possess quite good mechanical properties 
for being used in bone TE. On the other hand, the value for CS scaffolds are in good attainment with those for normal human articular cartilage, which has been shown to have a compressive modulus ranging from 1.9 to $14.4 \mathrm{MPa}[57,58]$. Thus, the HA/CS bilayered scaffolds demonstrated quite promising mechanical properties for being used in TE of osteochondral defects. Actually, it has been shown that the biomechanical properties of articular cartilage greatly depends on composition, density of its ECM and interstitial fluid flow (water and solutes) [59]. Therefore, in wet conditions is expected a reduction of the mechanical properties. However, it must be noted that after implanta- tion of the construct we expect to occur a matrix deposition and accumulation mediated by the cells, i.e. chondrocytes in the case of cartilage, and by this mean improve the mechanical function of the engineered cartilage [60].

The capability of a scaffold to uptake and preserve the water within the structure is an important feature for developing suitable TE constructs for regeneration of both cartilage and osteochondral defects, since cartilage possesses a high content of water where oxygen and nutrients are dissolved. The water uptake and weight loss of the HA/ CS bilayered scaffolds was investigated after soaking in PBS solution at physiological $\mathrm{pH}$, for 1 up to 30 days
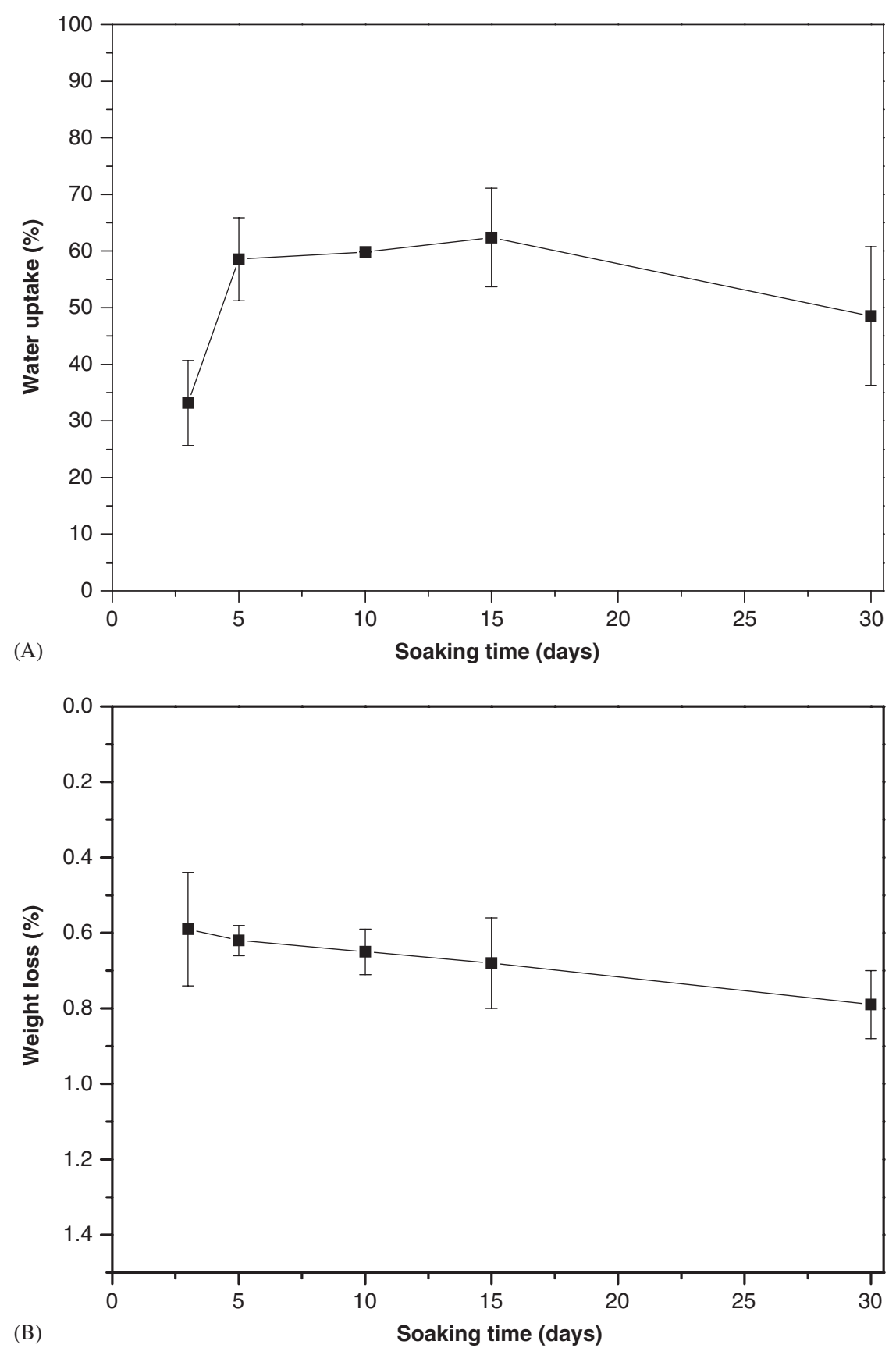

Fig. 6. HA/CS scaffolds after soaking in PBS solution for times ranging from 1 up to 30 days: water uptake (A) and weight loss (B). 
(Fig. 6). From Fig. 6A it can be seen that the water uptake profile of the $\mathrm{HA} / \mathrm{CS}$ scaffolds reach a maximum of swelling of approximately $65 \%(\mathrm{w} / \mathrm{w})$, after 5 days. From day 5 until day 30 the water uptake capability of the HA/ CS remained constant (Fig. 6A). After immersion of HA/ CS bilayered scaffolds in PBS, no significant changes on the weight loss were observed. In fact, the weight loss profile showed that from day 3 until day 30, the HA/CS scaffolds showed a reduction in weight of approximately $0.8 \%$ (Fig. 6B). It has been demonstrated that HA dissolves slowly, both in vitro and in vivo $[61,62]$. Therefore, this gradual weight loss should be mainly due to the slow loss of the highly hydrophilic CS scaffold by a solution-mediated dissolution, i.e. leaching of the water solubles rather than HA scaffold. A decrease in CS molecular weight lowers the water-uptake and favours dissolution [63]. Thus, the overall performance of the HA/ CS scaffolds may be easily tailored by using different formulations namely, varying the CS molecular weight and cross-linking [41]. Nevertheless, these results are quite interesting since the HA/CS bilayered scaffolds has shown to have enough stability, and preserve their size and physical integrity. This evidences their good performance for applications in TE of osteochondral defects and subsequent implantation.

\subsection{Cytotoxicity screening for the $H A$ scaffolds and $H A /$ CS bilayered scaffolds}

The intrinsic cytotoxicity of the HA scaffolds and HA/ CS bilayered scaffolds was assessed by culturing L929 cells with extract fluids for $72 \mathrm{~h}$. As observed in an inverted microscope cells exhibited a normal morphology proliferated well and established a monolayer (data not shown).

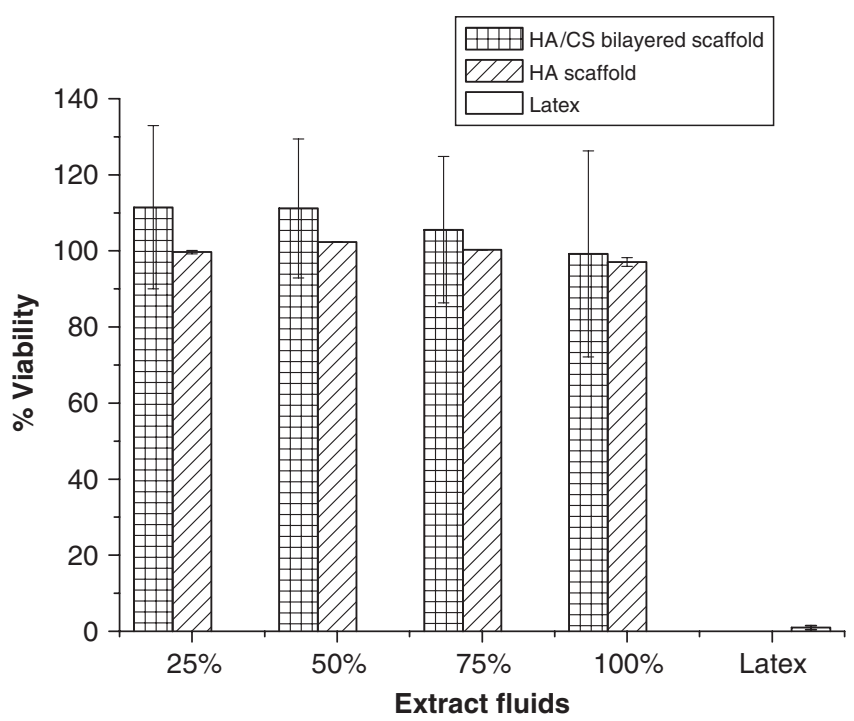

Fig. 7. Cytotoxicity screening for the HA scaffolds and HA/CS bilayered scaffolds. L929 cells were incubated with different concentrations of leachables obtained from HA scaffolds, HA/CS bilayered scaffolds, and latex (positive control).
Fig. 7 shows the cell viability assessed by carrying out the MTS test. From the results it is possible to assess that cells are viable in the presence of the HA and HA/CS scaffold leachables. In fact, the viability levels are similar among different $\mathrm{HA}$ and $\mathrm{HA} / \mathrm{CS}$ concentrations, reaching the maximum viability of $\sim 100 \%$. This shows that both HA scaffolds and HA/CS scaffolds do not exert any cytotoxic effect on L929 cells. On the contrary, Latex rubber results (positive control) performed in the same conditions; do not overtake $1.0 \%$ of viable cells.

\subsection{In vitro assessement of GBMCs adhesion, proliferation and differentiation}

The current investigations using biodegradable implants seeded MSCs have shown to be effective on the repair of osteochondral defects, in vivo [19]. In this work, we first analysed the ability of the HA porous layer to successfully support the GBMCs adhesion and functions, in vitro (Phase IA). As mentioned above, when treating osteochondral defects this 'bone-like' layer is aimed at provide the repair of the subchondral bone [64], while providing a good fixation on the underlying bone, during cartilage regeneration. Fig. 8 shows the SEM micrographs obtained from samples resulting from culturing GBMCs onto the HA porous layer in osteogenic medium, for 14 days. It is possible to observe the high cellular density on the surface of the HA porous layer, which indicates that cells adhered and grew favourably (Fig. 8A). Additionally, it is also possible to observe that cells did not obstruct the pores of the scaffold at the surface (Fig. 8B), and perfectly adhere, spread actively and presented a flatten morphology onto the surface of the biomaterial (Fig. 8C). In fact, the transversal section analysis indicates that cells were able to penetrate deeper into the scaffold core (Fig. 8D). This is an important observation since a good cell distribution within the whole scaffold greatly affects the overall performance of the construct (e.g. not limiting the diffusion of nutrients and oxygen) and shows that scaffold architecture allowed cells ingrowths and a sufficient diffusion of nutrients. Additionally, the formation of cells micovilli is also observed, which is suggestive of cell activation [65]. In our opinion, this result is quite promising since it demonstrates that the HA porous layer possess an adequate pore size and pore distribution to effectively allow the cells to adhere and maintain their functions. Analysis of DNA values showed a significant enhancement comparatively to initial time points (Fig. 9). The cell number increased, and hence a high cellular proliferation occurred in the presence of osteogenic media. The DNA biochemical analysis was corroborated by MTS assay (Fig. 10) showing that cells not only proliferated well in HA porous layer but also were viable. These results illustrate that HA porous layer is a suitable 3D support for cellular proliferation. The functional activity of the GBMCs on the HA porous layer was determined by quantifying the ALP activity (Fig. 11). From days 0 to 3, 

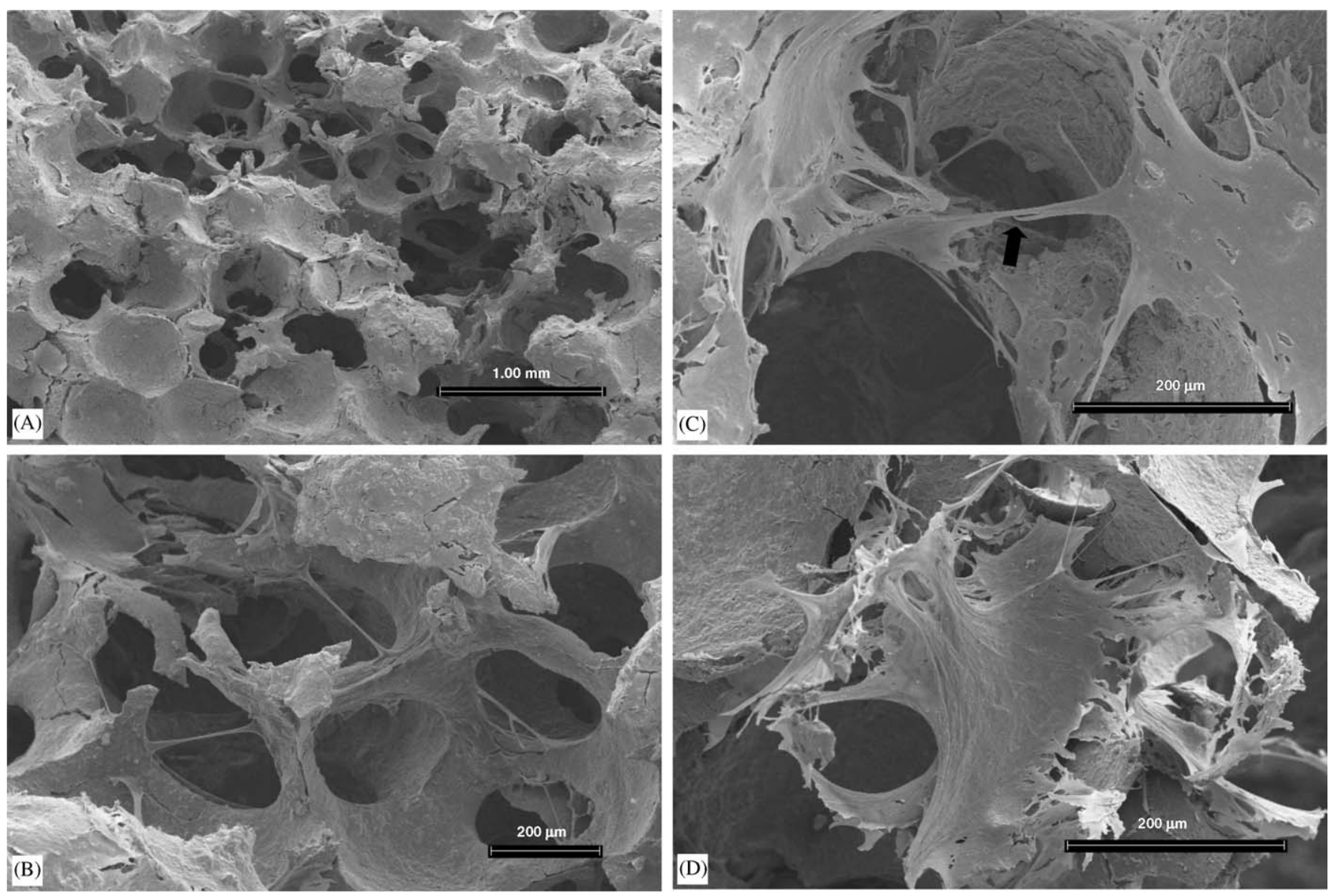

Fig. 8. SEM micrographs of the HA scaffold seeded with GBMCs and cultured for 14 days in osteogenic media: surface of the cell-HA constructs (A, B), GBMCs infiltration into a HA macropore (C), and GBMCs on the core of the HA scaffolds (D).

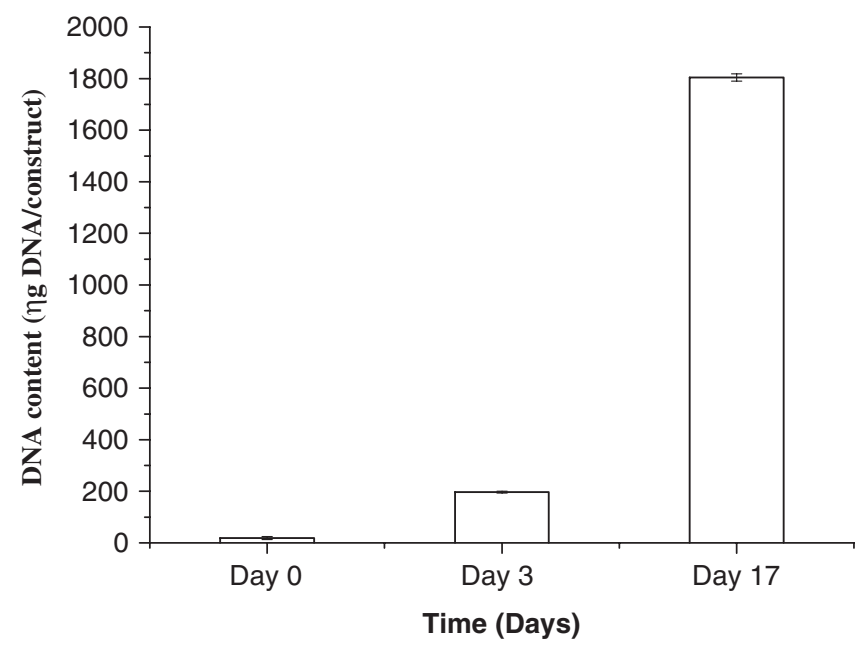

Fig. 9. DNA content of GBMCs cultured on the HA scaffolds versus culture time.

cells were not cultured with osteogenic medium; so, ALP levels refer only to basal levels of ALP activity in GBMCs. Although, the higher ALP results shows that there is an enhancement of the osteoblastic phenotype expression

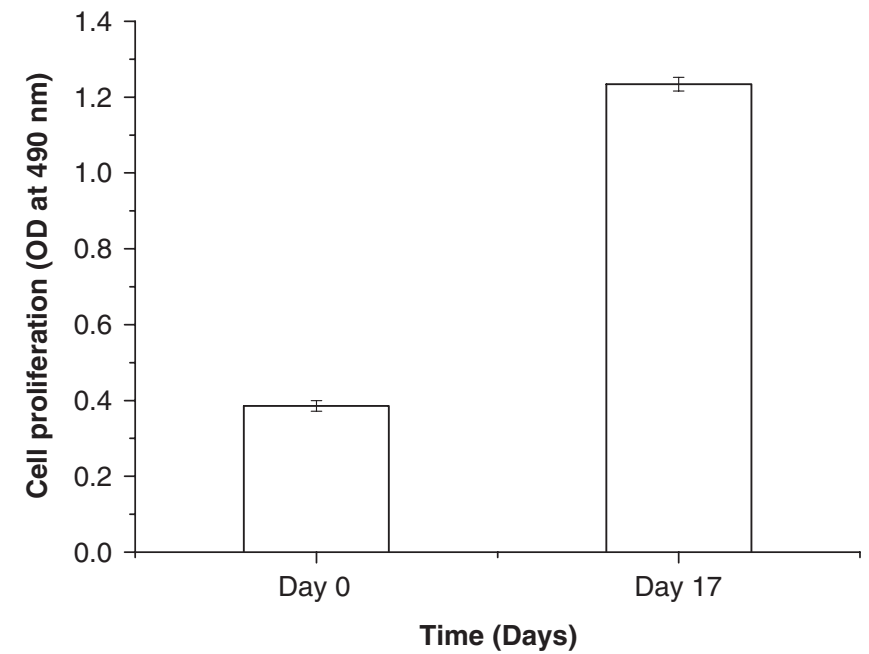

Fig. 10. Proliferation levels of GBMCs on the HA scaffolds after 3 and 14 days of osteogenic culture, as assessed by an MTS method.

levels, which evidences the presence of osteoblast cells, after 14 days (day 17) of culturing in the osteogenic medium (Fig. 11). Fig. 12 shows the immunocytochemistry preliminary results for cell-HA scaffold constructs after 14 
days of culturing. The labelling was quite intense for osteopontin, which demonstrates that osteoblast differentiation was achieved in these constructs (Fig. 12A). Immunolabeling for collagen type I was also detected, thus showing the production of collagenous matrix (Fig. 12C). Therefore, this data confirm that GBMCs were able to differentiate in the HA layer after culturing in an osteogenic media for 14 days.

GBMCs seeded onto CS layer present a good viability and proliferation (data not showed). SEM micrographs show the attachment of cells possessing size and shape

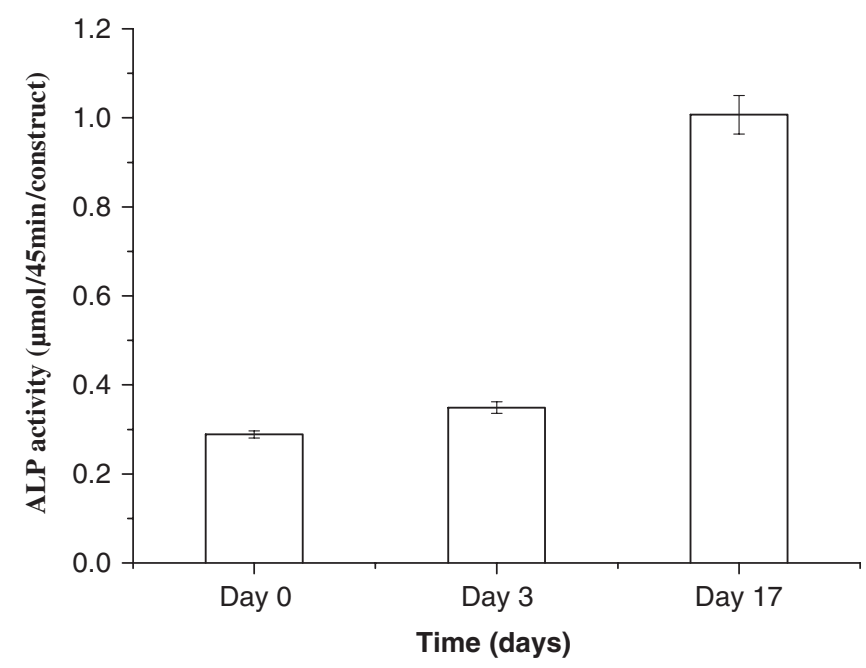

Fig. 11. ALP activity assay of GBMCs cells cultured on the HA scaffolds. consistent with those of chondrocytes throughout the scaffolds, i.e. round chondrocyte-like cells (Fig. 13). It is also possible to observe a good distribution of cells and maintenance of the rounded cell morphology after day 28 (Fig. 13A). At higher magnification the moderate cell adhesion to the substrate can also be seen (Fig. 13B), which is generally indicative of a cell performing its differentiation function [66]. Despite, cell numbers and penetration within scaffolds appeared to improve in areas presenting larger and interconnected pores.

Glycosaminoglycans (GAGs) are an important component of proteoglycan and are typically present in the cartilaginous ECM [67]. GAGs content was determined to assess the formation of newly formed ECM and thus if occur the differentiation of GBMCs into chondrocytes in these cell-scaffold constructs, at days 7, 21 and 28 (Fig. 14). The biochemical analysis demonstrated that the content of GAGs increased from days 7 to 21 , indicating that occur biosynthesis due to the differentiation of the GBMCs into the chondrogenic lineage. GAGs levels seems to be low; however it was not found in the literature any reference values to compare with. Nevertheless, CS scaffolds obtained by a freeze-drying technique suggested to be a suitable 3D support for chondrogenic differentiation of GBMCs, and their maintenance over a period of 28 days.

Future studies will be designed to investigate the capacity of the HA/CS bilayered scaffolds to favour simultaneous but independent osteoblasts and chondrocytes proliferation and differentiation upon seeding GBMCs, leading to the formation of adequate tissue substitutes for the regeneration of
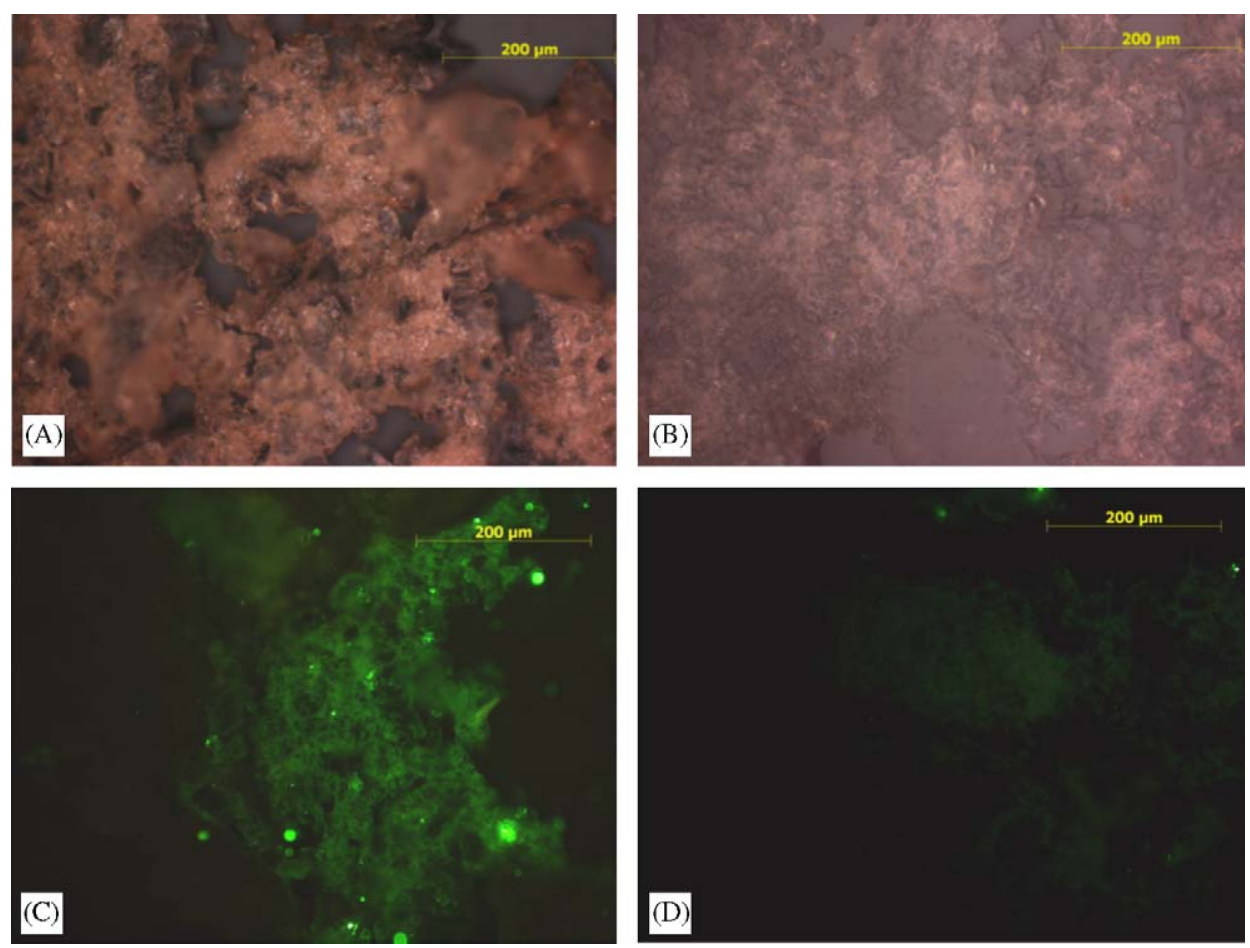

Fig. 12. Immunolabeling for osteopontin marker (A) and respective negative control (without antibody) (B) on the cell-HA scaffold constructs after 14 days of culturing. Immunolabeling for collagen type I marker (C) and respective negative control (without antibody) (D) on the cell-HA scaffold constructs after 14 days of culturing. 

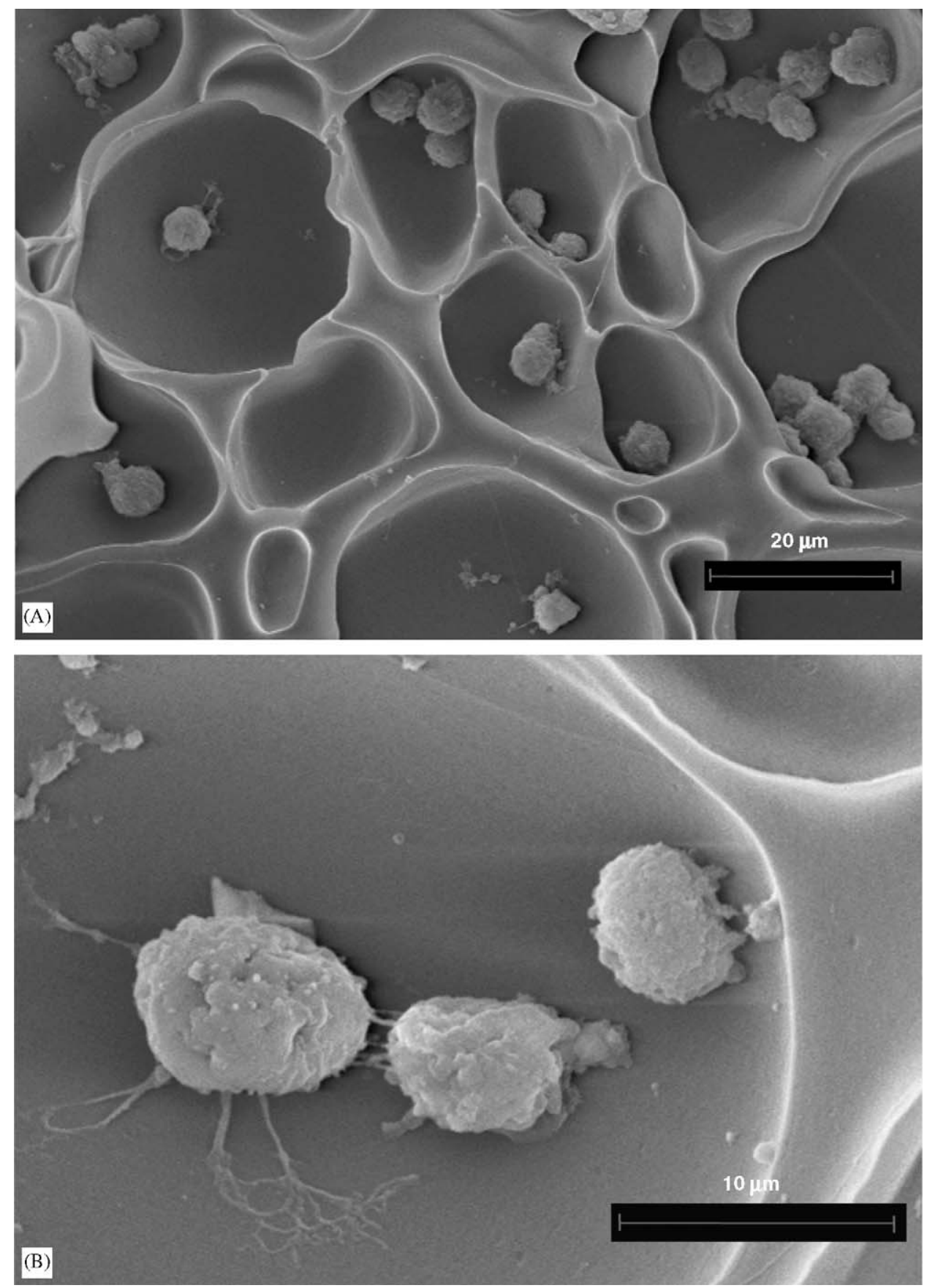

Fig. 13. SEM micrographs of the CS layer seeded with GBMCs after 28 days of culturing (A, B).

osteochondral defects (Phase II). This will be achieved using a culturing system such as the ones proposed by Martin et al. [68], which are specifically designed for this purpose and allow to culture simultaneously the HA and CS layers in separate culture medium that will direct cell differentiation into the required phenotypes.

\section{Conclusions}

This work demonstrates the feasibility to prepare hydroxyapatite/chitosan bilayered scaffolds by means of an innovative method that combines a sintering and a freeze-drying technique. The novel 3D-macroporous hydroxyapatite/chitosan bilayered scaffolds exhibit physicochemical properties that appear to make them a suitable candidate to be used as a supportive structure for cells functions. Moreover, the in vitro cell culture studies demonstrated that both HA and CS layers provide an adequate 3D support for the attachment, proliferation and differentiation of GBMCs into osteoblasts and chondrocytes, respectively. The $\mathrm{HA} / \mathrm{CS}$ bilayered scaffolds are advantageous by several reasons, namely, they can be 


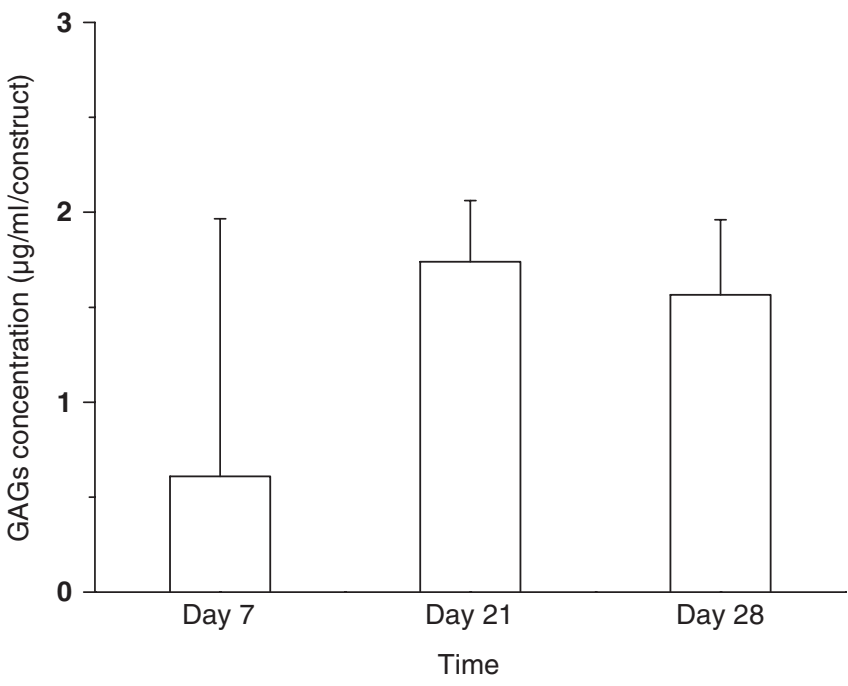

Fig. 14. GAGs quantification assay of GBMCs cells cultured on the CS layer.

designed with several sizes and controlled architecture to fit patient specific injuries and cell functions, respectively. The HA/CS bilayered scaffolds showed promising biological behaviour and may therefore find applications in tissue engineering of bone and osteochondral defects.

\section{Acknowledgements}

Funding was provided by Portuguese Foundation for Science and Technology (FCT) through POCTI and/or FEDER programmes. Joaquim M. Oliveira was also supported by a PhD scholarship from Portuguese Foundation for Science and Technology (FCT) (SFRH/BD/21786/ 2005). We are thankful to Materialise (Belgium) for the MIMICS $^{\circledR}$ software provided and LBI, namely Gerald Zanoni (Vienna, Austria) for the $\mu$-CT scans in the frame of the European Union funded STREP Project HIPPOCRATES (NMP3-CT-2003-505758). This work was also carried out under the scope of the European NoE EXPERTISSUES (NMP3-CT-2004-500283).

\section{References}

[1] Temenoff JS, Mikos AG. Review: tissue engineering for regeneration of articular cartilage. Biomaterials 2000;21:431-40.

[2] Cohen NP, Foster RJ, Mow VC. Composition and dynamics of articular cartilage: structure, function and maintaining healthy state. J Orthop Sports Phys Ther 1998;28:203-15.

[3] Aigner T, Stove J. Collagens - major component of the physiological cartilage matrix, major target of cartilage degeneration, major tool in the cartilage repair. Adv Drug Deliv Rev 2003;55:1569-93.

[4] Kuettner KE, Cole AA. Review: cartilage degeneration in different human joints. Osteoarthr Cartilage 2005;13:93-103.

[5] Buckwalter JA. Articular cartilage: injuries and potential for healing. J Orthop Sports Phys Ther 1998;28:192-202.

[6] Redman SN, Oldfield SF, Archer CW. Current strategies for articular cartilage repair. Eur Cells Mater 2005;9:23-32.

[7] Glowacki J. In vitro engineering of cartilage. J Rehab Res Dev 2000;37:171-7.
[8] Miller BS, Steadman JR, Briggs KK, Rodrigo JJ, Rodkey WG. Patient satisfaction and outcome after microfracture of degenerative knee. J Knee Surg 2004;17:13-7.

[9] Krishnan SP, Skinner JA. (i) Novel treatments for early osteoarthritis of the knee. Curr Orthop 2005;19:407-14.

[10] Akizuki S, Yasukawa Y, Takizawa T. Does arthroscopic abrasion arthroplasty promote cartilage regeneration in osteoarthritic knees with eburnation? A prospective study of high tibial osteotomy with abrasion arthroplasty versus high tibial osteotomy alone. Arthroscopy 1997;13:9-17.

[11] Shapiro F, Koide S, Glimcher MJ. Cell origin and differentiation in the repair of full-thickness defects of articular cartilage. J Bone J Surg Am 1993;75:532-53.

[12] Tibesku CO, Szuwart T, Kleffner TO, Schlegel PM, Jahn UR, Van Aken $\mathrm{H}$, et al. Hyaline cartilage degenerates after autologous osteochondral transplantation. J Orthop Res 2004;22:1210-4.

[13] Gillogly SD, Voight M, Blackburn T. Treatment of articular cartilage defects of the knee with autologous chondrocyte implantation. J Orthop Sports Phys Ther 1998;28:241-51.

[14] Minas T. Autologous chondrocyte implantation in arthritic knee. Orthopedics 2003;26:945-7.

[15] Brittberg M. Autologous chondrocyte transplantation. Clin Orthop 1999;367:S147-55.

[16] Glowacki TJ, Trepman E, Folkman J. Cell shape and phenotypic expression in chondrocytes. Proc Soc Exp Biol Med 1983;172:93-8.

[17] Yoo J, Barthel T, Nishimura K, Solchaga L, Caplan AI, Goldberg V, et al. The chondrogenic potential of human bone-marrow-derived mesenchymal progenitor cells. J Bone J Surg Am 1998;80:1745-57.

[18] O'Driscoll SW. The healing and regeneration of articular cartilage. J Bone J Surg 1998;80-A:1795-812.

[19] Uematsu K, Hattori K, Ishimoto $Y$, Yamauchi J, Habata $T$, Takakura Y, et al. Cartilage regeneration using mesenchymal stem cells and a three-dimensional poly-lactic-glycolic acid (PLGA) scaffold. Biomaterials 2005;26:4273-9.

[20] Solchaga L, Temenoff J, Gao J, Mikos A, Caplan A, VM G. Repair of osteochondral defects with hyaluronan- and polyester-based scaffolds. Osteoarthr Cartilage 2005;13:297.

[21] Lima EG, Mauck RL, Han SH, Park S, Ng KW, Ateshian GA, et al. Functional tissue engineering of chondral and osteochondral constructs. Biorheology 2004;41:577-90.

[22] Schaefer D, Martin I, Shastri P, Padera RF, Langer R, Freed LE, et al. In vitro generation of osteochondral composites. Biomaterials 2000;21:2599-606.

[23] Schaefer D, Martin I, Jundt G, Seidel J, Heberer M, Grodzinsky A, et al. Tissue-engineered composites for the repair of large osteochondral defects. Arthritis Rheum 2002;46:2524-34.

[24] Gao J, Dennis JE, Solchaga LA, Goldberg VM, Caplan AI. Repair of osteochondral defect with tissue-engineered two-phase composite material of injectable calcium phosphate and hyaluronan sponge. Tissue Eng 2002;8:827-37.

[25] Schek RM, Taboas JM, Segvich SJ, Hollister SJ, Krebsbach PH. Engineered osteochondral grafts using biphasic composite solid freeform fabricated scaffolds. Tissue Eng 2004;10:1376-85.

[26] Kotobuki N, Ioku K, Kawagoe D, Fujimori H, Goto S, Ohgushi H. Observation of osteogenic differentiation cascade of living mesenchymal stem cells on transparent hydroxyapatite ceramics. Biomaterials 2005;26:779-85.

[27] Kasten P, Vogel J, Luginbuhl R, Niemeyer P, Tonak M, Lorenz H, et al. Ectopic bone formation associated with mesenchymal stem cells in a resorbable calcium deficient hydroxyapatite carrier. Biomaterials 2005;26:5879-89.

[28] Livingston Arinzeh T, Tran T, Mcalary J, Daculsi G. A comparative study of biphasic calcium phosphate ceramics for human mesenchymal stem-cell-induced bone formation. Biomaterials 2005;26: 3631-8.

[29] Lu JX, Prudhommeaux F, Meunier A, Sedel L, Guillemin G. Effects of chitosan on rat knee cartilages. Biomaterials 1999;20: $1937-44$. 
[30] Di Martino A, Sittinger M, Risbud MV. Chitosan: a versatile biopolymer for orthopaedic tissue-engineering. Biomaterials 2005; 26:5983-90.

[31] Yamane S, Iwasaki N, Majima T, Funakoshi T, Masuko T, Harada $\mathrm{K}$, et al. Feasibility of chitosan-based hyaluronic acid hybrid biomaterial for a novel scaffold in cartilage tissue engineering. Biomaterials 2005;26:611.

[32] Jiang Y, Jahagirdar BN, Reinhardt RL, Schwartz RE, Keene CD, Ortiz-Gonzalez XR, et al. Pluripotency of mesenchymal stem cells derived from adult marrow. Nature 2002;418:41-9.

[33] Reyes M, Lund T, Lenvik T, Aguiar D, Koodie L, Verfaillie CM. Purification and ex vivo expansion of postnatal human marrow mesodermal progenitor cells. Blood 2001;98:2615-25.

[34] Im II G, Shin Y-W, Lee K-B. Do adipose tissue-derived mesenchymal stem cells have the same osteogenic and chondrogenic potential as bone marrow-derived cells? Osteoarthr Cartilage 2005;13:845.

[35] Kitamura S, Ohgushi H, Hirose M, Funaoka H, Takakura Y, Ito H. Osteogenic differentiation of human bone marrow-derived mesenchymal cells cultured on alumina ceramics. Artif Organs 2004;28:72-82.

[36] Caplan AI, Elyaderani M, Mochizuki Y, Wakitani S, Goldberg VM. Principles of cartilage repair and regeneration. Clin Orthop Relat Res 1997;342:254-69.

[37] Uemura T, Dong J, Wang Y, Kojima H, Saito T, Iejima D, et al. Transplantation of cultured bone cells using combinations of scaffolds and culture techniques. Biomaterials 2003;24:2277.

[38] Ohgushi H, Kotobuki N, Funaoka H, Machida H, Hirose M, Tanaka $\mathrm{Y}$, et al. Tissue engineered ceramic artificial joint-ex vivo osteogenic differentiation of patient mesenchymal cells on total ankle joints for treatment of osteoarthritis. Biomaterials 2005;26:4654-61.

[39] Rahaman MN, Mao JJ. Stem cell-based composite tissue constructs for regenerative medicine. Biotechnol Bioeng 2005;91:261-84.

[40] Oliveira JM, Silva SS, Mano JF, Reis RL. Innovative technique for the preparation of porous bilayer hydroxyapatite/chitosan scaffolds for osteochondral applications. Kyoto (JPN), Zurich, Switzerland: Key Eng Mater, Trans Tech Pub; 2006.

[41] Silva SS, Oliveira JM, Mano JF, Reis RL. Preparation and characterization of novel chitosan/soy protein porous for tissue engineering applications. Adv Mater Forum 2006;514-516:1000-4.

[42] Gomes ME, Reis RL, Cunha AM, Blitterswijk CA, de Bruijn JD. Cytocompatibility and response of osteoblastic-like cells to starchbased polymers: effect of several additives and processing conditions. Biomaterials 2001;22:1911.

[43] Hollander AP, Hatton PV. Biopolymer methods in tissue engineering (methods in molecular biology series). Totowa, NJ: Human Press Inc.; 2004.

[44] Kupper JH, van Gool L, Burkle A. Molecular genetic systems to study the role of poly(ADP-ribosyl)ation in the cellular response to DNA damage. Biochimie 1995;77(6):450.

[45] Oliveira JM, Silva SS, Malafaya PB, Rodrigues MT, Gomes ME, Mano JF, et al. Development and physichochemical characterization of novel hydroxyapatite scaffolds for bone tissue engineering applications. J Mater Sci-Mater Med 2006 (in press).

[46] Yamaguchi I, Itoh S, Suzuki M, Sakane M, Osaka A, Tanaka J. The chitosan prepared from crab tendon $\mathrm{I}$ : the characterization and mechanical properties. Biomaterials 2003;24:2031-6.

[47] Kolhe P, Kannan RM. Improvement in ductibility of chitosan through blending and copolymerization with PEG: FTIR investigation of molecular interactions. Biomacromolecules 2003;4:173-80.

[48] Raynaud S, Champion E, Bernache-Assollant D, Thomas P. Calcium phosphate with variable $\mathrm{Ca} / \mathrm{P}$ atomic ratio. I. Synthesis, characterization and thermal stability of powders. Biomaterials 2002; 23:1065-72.

[49] Tampieri A, Celotti G, Szontagh F, Landi E. Sintering and characterization of HA and TCP bioceramics with control of their strength and phase purity. J Mater Sci-Mater Med 1997; 8:29-37.

[50] Mostafa NY. Characterization, thermal stability and sintering of hydroxyapatite powders prepared by different routes. Mater Chem Phys 2005;94:333.

[51] Kotobuki N, Ioku K, Kawagoe D, Fujimori H, Goto S, Ohgushi H. Observation of osteogenic differentiation cascade of living mesenchymal stem cells on transparent hydroxyapatite ceramics. Biomaterials 2005;26:779.

[52] Cyster LA, Grant DM, Howdle SM, Rose FRAJ, Irvine DJ, Freeman D, et al. The influence of dispersant concentration on the pore morphology of hydroxyapatite ceramics for bone tissue engineering. Biomaterials 2005;26:697.

[53] Ho M-H, Kuo P-Y, Hsieh H-J, Hsieh T-Y, Hou L-T, Lai J-Y, et al. Preparation of porous scaffolds by using freeze-extraction and freezegelation methods. Biomaterials 2004;25:129-38.

[54] Madihally SV, Matthew HWT. Porous chitosan scaffolds for tissue engineering. Biomaterials 1999;20:1133-42.

[55] Karageorgiou V, Kaplan D. Porosity of 3D biomaterial scaffolds and osteogenesis. Biomaterials 2005;26:5474-91.

[56] Hutmacher DW. Scaffolds in tissue engineering bone and cartilage. Biomaterials 2000;21:2529-43.

[57] Zheng-Qiu G, Jiu-Mei X, Xiang-Hong Z. The development of artificial articular cartilage-PVA-hydrogel. Biomed Mater Eng 1998;8:75-81.

[58] Magnussen RA, Guilak F, Vail TP. Cartilage degeneration in postcollapse cases of osteonecrosis of the human femoral head: altered mechanical properties in tension, compression, and shear. J Orthop Res 2005;23:576.

[59] Evans RC, Quinn TM. Solute diffusivity correlates with mechanical properties and matrix density of compressed articular cartilage. Arch Biochem Biophys 2005;442:1.

[60] Miyata S, Furukawa KS, Ushida T, Nitta Y, Tateishi T. Static and dynamic mechanical properties of extracellular matrix synthesized by cultured chondrocytes. Mater Sci Eng C 2004;24:425.

[61] Driessens FCM, Ramselaar MMA, Schaken HG, Stols ALH, Van Mullem PJ, de Wijn JR. Chemical reactions of calcium phosphate implants after implantation in vivo. J Mater Sci-Mater Med 1992;3:413-7.

[62] Klein CPAT, de Blieck-Hogemrst JMA, Wolket JGC, de Groot K. Studies of the solubility of different calcium phosphate ceramic particles in vitro. Biomaterials 1990;11:509.

[63] Berger J, Reist M, Mayer JM, Felt O, Peppas NA, Gurny R. Structure and interactions in covalently and ionically crosslinked chitosan hydrogels for biomedical applications. Eur J Pharm Biopharm 2004;57:19-34.

[64] Tamai N, Myoui A, Hirao M, Kaito T, Ochi T, Tanaka J, et al. A new biotechnology for articular cartilage repair: subchondral implantation of a composite of interconnected porous hydroxyapatite, synthetic polymer (PLA-PEG), and bone morphogenetic protein2 (rhBMP-2). Osteoarthr Cartilage 2005;13:405.

[65] Xynos ID, Hukkanen MVJ, Batten JJ, Buttery LD, Hench LL, Polak JM. Bioglass 45S5 stimulates osteoblast turnover and enhances bone formation in vitro: implications and applications for bone tissue engineering. Calcif Tissue Int 2000;67:321-9.

[66] Yaylaoglu MB, Yildiz C, Korkusuz F, Hasirci V. A novel osteochondral implant. Biomaterials 1999;20:1513-20.

[67] Barnewitz D, Endres M, Kruger I, Becker A, Zimmermann J, Wilke I, et al. Treatment of articular cartilage defects in horses with polymer-based cartilage tissue engineering grafts. Biomaterials 2006;27:2882-9.

[68] Wendt D, Jakob M, Martin I. Bioreactor-based engineering of osteochondral grafts: from model systems to tissue manufacturing. J Biosci Bioeng 2005;100:489-94. 